\title{
Acceptability and feasibility of the 'DASH for Asthma' intervention in a randomized controlled trial pilot study
}

\author{
Andrea C Blonstein ${ }^{1} \uparrow$, Nan Lv ${ }^{1} \uparrow$, Carlos A Camargo Jr ${ }^{2}$, Sandra R Wilson ${ }^{1,3}$, \\ A Sonia Buist ${ }^{4}$, Lisa G Rosas ${ }^{1,3}$, Peg Strub ${ }^{5}$ and Jun Ma ${ }^{1,3,6, *}$ \\ 'Palo Alto Medical Foundation Research Institute, Palo Alto, CA, USA: ${ }^{2}$ Department of Emergency Medicine, \\ Massachusetts General Hospital, Harvard Medical School, Boston, MA, USA: ${ }^{3}$ Department of Medicine, Stanford \\ University School of Medicine, Stanford, CA, USA: ${ }^{4}$ Pulmonary \& Critical Care Medicine, Oregon Health \& Science \\ University, Portland, OR, USA: ${ }^{5}$ Department of Allergy, Asthma, and Immunology, The Permanente Medical Group, \\ San Francisco Medical Center, San Francisco, CA, USA: ${ }^{6}$ Department of Health Policy and Administration, University \\ of Illinois at Chicago School of Public Health, Chicago, IL 60607, USA
}

Submitted 25 March 2015: Final revision received 2 0ctober 2015: Accepted 10 November 2015: First published online 10 December 2015

\begin{abstract}
Objective: 'DASH for Asthma' ( $n$ 90) was a 6-month randomized controlled trial that demonstrated potential benefits of a DASH (Dietary Approaches to Stop Hypertension) behavioural intervention for improving diet quality and asthma control by comparing intervention to usual care in adults with uncontrolled asthma. The present study examined acceptability and feasibility of the intervention from the perspective of intervention participants and lifestyle coaches.

Design: Grounded in Social Cognitive Theory, the 3-month intensive stage, including three individual and eight group sessions, focused on diet modifications and behavioural self-regulation. The 3-month maintenance stage contained telephone consultations. Participants and lifestyle coaches completed surveys including 5-point Likert scales and open-ended questions. We analysed data using descriptive and inductive content analyses.

Subjects: Forty-six intervention participants (survey response rate was 65-72\%) and two lifestyle coaches.

Results: Participants and lifestyle coaches were highly satisfied (all mean ratings >4) with individual and group sessions. Participants identified mastery of knowledge and skills (awareness, goal setting, self-monitoring, problem solving), social learning (class members sharing experiences and ideas) and good coaching skills (reflective listening, empathy, motivational counselling) as important contributors to selfefficacy and programme satisfaction. Participants also valued personalized feedback received in individual sessions. Lifestyle coaches viewed participant engagement as a facilitator to effective sessions. Finally, participants and lifestyle coaches identified food tasting as beneficial for observational learning and facilitation of participant engagement. High class attendance and self-monitoring rate also reflected the high engagement among participants.

Conclusions: The DASH behavioural intervention was feasible and highly acceptable to participants with uncontrolled asthma and lifestyle coaches.
\end{abstract}

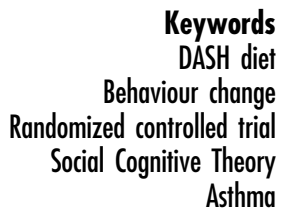

Keywords

ASH diet

Behaviour change Social Cognitive Theory Asthma
Asthma prevalence has increased globally in recent years, with 334 million people estimated to have asthma in $2014^{(1)}$. In the USA, approximately 26 million Americans were afflicted with asthma in $2010^{(2)}$. Dietary factors have been implicated in this increase ${ }^{(3,4)}$. Some studies have also documented an association of asthma control with specific foods, food groups and dietary patterns ${ }^{(5-7)}$.

Cross-sectional and prospective cohort studies have shown that the Mediterranean diet has beneficial effects for

$\dagger$ Andrea C Blonstein and Nan Lv are dual first authors. asthma symptoms and control in adults and children ${ }^{(5,8-10)}$. The DASH (Dietary Approaches to Stop Hypertension) diet, a healthy eating pattern similar to the Mediterranean diet, is characterized by high intakes of fruit, vegetables, low-fat or fat-free dairy products, whole grains, nuts, seeds and legumes, low intakes of total and saturated fat, sodium and added sugars, and moderate intake of alcohol ${ }^{(11)}$. It is recommended by the US Department of Agriculture ${ }^{(12)}$ based on its proven efficacy for the prevention and treatment of high blood pressure ${ }^{(13-16)}$ and other possible health benefits (e.g. reduced risks of CVD and 
type 2 diabetes) ${ }^{(17,18)}$. However, no observational or experimental studies to date have evaluated the effects of DASH on asthma control.

To address this critical gap in the literature, 'DASH for Asthma' ( $n$ 90) was a randomized controlled trial pilot study that examined the feasibility and potential efficacy of a DASH behavioural intervention on asthma control by comparing the intervention to usual care in adults with uncontrolled asthma ${ }^{(19)}$. At 6 months, eighty-three (92\%) participants were assessed and the results showed that the DASH behavioural intervention significantly improved diet quality and increased the proportion of participants achieving minimal clinically important improvement in asthma control among adults with uncontrolled asthma; thus a full-scale efficacy trial is warranted ${ }^{(20)}$. The purpose of the current article is to describe the behavioural intervention developed to promote adherence to the DASH eating pattern and to examine acceptability and feasibility of the intervention from the perspective of intervention participants and lifestyle coaches by (i) tracking participant class attendance and self-monitoring behaviour and (ii) conducting surveys with open- and closed-ended responses after each intervention session among participants and lifestyle coaches.

\section{Methods}

'DASH for Asthma' was conducted according to the guidelines laid down in the Declaration of Helsinki and all procedures involving human subjects/patients were approved by an Institutional Review Board of the Kaiser Foundation Research Institute in Northern California and the study Data and Safety Monitoring Board. Written informed consent was obtained from all subjects/patients. Details of the study design were previously published ${ }^{(19)}$.

\section{Study participants}

Participants were recruited in three cohorts from the Kaiser Permanente medical centres in San Francisco and Hayward, California, and forty-six of the ninety participants were randomized to the intervention. Inclusion criteria included English-speaking men and women of all ethnic groups, aged 18-70 years, BMI between 18.5 and $39.9 \mathrm{~kg} / \mathrm{m}^{2}$, low diet quality defined as a composite DASH concordance index $<6$ (out of 9) ${ }^{(21)}$ and clinically confirmed uncontrolled persistent asthma. Individuals with significant medical or psychiatric conditions (e.g. chronic obstructive pulmonary disease, CVD, stroke, diabetes, bipolar or psychotic disorder) or special life circumstances (e.g. planned relocation, pregnancy, active attempt at weight loss) were excluded. At baseline, only a small percentage of the intervention participants reported being current smokers. Of the forty-six intervention participants, $81 \%$ had never smoked (i.e. smoked $\leq 20$ packs of cigarettes in lifetime and $\leq 1$ cigarette per day for 1 year);
$4 \%$ were current smokers; and $15 \%$ were former smokers at baseline. The prevalence of smoking was similar among controls.

\section{'DASH for Asthma' intervention}

Although the intervention under study focused on dietary modifications, smoking cessation is integral to standard care for asthma patients who smoke, which all participants in the study had access to as members of the Kaiser Permanente in Northern California, regardless of their random assignment.

A comprehensive intervention manual consisting of lifestyle coach scripts, participant handouts, and action planning and tracking worksheets was developed. Publically available materials from research-based interventions (PREMIER ${ }^{(22)}$ and Look AHEAD ${ }^{(23)}$ ) and DASH principles in the US 2010 Dietary Guidelines ${ }^{(12)}$ were adapted, where appropriate.

\section{Theoretical basis and goals}

Social Cognitive Theory (SCT) formed the theoretical basis of the intervention as summarized in Table $1^{(24)}$. A goal-based approach utilizing four primary and four secondary goals guided participants' efforts towards achievement of the DASH eating pattern. Primary goals included daily recommendations for: (i) fruit and vegetable servings (usually 7-8 for women or 8-10 for men); (ii) low-fat or fat-free dairy food servings (usually 2-3); (iii) total fat grams ( $27 \%$ of estimated energy needs); and (iv) sodium intake (less than $2300 \mathrm{mg} / \mathrm{d}$ ). All but the sodium goal were energy-based. Secondary goals were to: (i) increase intake of whole grains (to 3 servings/d); (ii) increase intake of nuts, seeds and legumes (to 5 servings/week); (iii) reduce intake of high-sugar foods (to no more than 5 servings/week); and (iv) limit alcohol intake (to no more than $1 \mathrm{drink} / \mathrm{d}$ for women and 2 drinks/d for men). Participants were encouraged to achieve and maintain adherence to primary goals before moving forward with secondary goals.

\section{Curriculum}

The 6-month intervention had a 3-month intensive stage (including three individual sessions and eight group sessions) and a 3-month maintenance stage (including a set of three monthly or more frequent telephone consultations), led by two lifestyle coaches who are registered dietitians. The intervention was conducted for a total of five times with participants enrolled across the three different cohorts. Curriculum topics included nutrition information and behaviour modification strategies, with an emphasis on sustainable changes to eating habits and practices (Table 1). Participants received a binder to which handouts, worksheets and home activity checklists were added at each successive session. 
Table 1 Correspondence between 'DASH for Asthma' curriculum content and Social Cognitive Theory (SCT) constructs

\begin{tabular}{|c|c|c|c|c|c|}
\hline Session* & Behavioural capability & Self-regulation & Self-efficacy & $\begin{array}{l}\text { Outcome expectations/Reciprocal } \\
\text { determinism }\end{array}$ & $\begin{array}{l}\text { Facilitation/ } \\
\text { Observational learning }\end{array}$ \\
\hline $\begin{array}{l}\text { 1. Programme } \\
\text { overview }\end{array}$ & - Introduce self-monitoring skills & $\begin{array}{l}\text { - Encourage continuous } \\
\text { self-monitoring }\end{array}$ & & $\begin{array}{l}\text { - Elicit personal intervention } \\
\text { outcome expectations }\end{array}$ & $\begin{array}{l}\text { - Provide self-regulation } \\
\text { tools (e.g. food diary, } \\
\text { fat and sodium } \\
\text { counter) }\end{array}$ \\
\hline $\begin{array}{l}\text { 2. Programme } \\
\text { goals and food } \\
\text { groups }\end{array}$ & $\begin{array}{l}\text { - Instruct on food groups, measuring } \\
\text { food, self-monitoring }\end{array}$ & $\begin{array}{l}\text { - Encourage continuous } \\
\text { self-monitoring }\end{array}$ & $\begin{array}{l}\text { - Review home activities, reinforce } \\
\text { progress, solve problems } \\
\text { - Review food diary, provide } \\
\text { feedback }\end{array}$ & $\begin{array}{l}\text { - Address benefits of meeting } \\
\text { DASH diet goals }\end{array}$ & $\begin{array}{l}\text { Demonstrate dietary } \\
\text { principles through } \\
\text { food tasting }\end{array}$ \\
\hline 3. Dietary fat & $\begin{array}{l}\text { - Encourage small changes to } \\
\text { facilitate healthy habits } \\
\text { - Instruct on identifying and reducing } \\
\text { dietary fat } \\
\text { - Teach SMART goal-setting steps }\end{array}$ & $\begin{array}{l}\text { - Encourage self-monitoring } \\
\text { and goal setting }\end{array}$ & $\begin{array}{l}\text { - Review home activities, reinforce } \\
\text { progress, solve problems } \\
\text { - Review food diary, provide } \\
\text { feedback }\end{array}$ & $\begin{array}{l}\text { - Address benefits of reducing fat, } \\
\text { making small changes to } \\
\text { facilitate healthy habits, and } \\
\text { goal setting }\end{array}$ & $\begin{array}{l}\text { - Demonstrate dietary } \\
\text { principles through } \\
\text { food tasting }\end{array}$ \\
\hline $\begin{array}{l}\text { 4. Dietary } \\
\text { sodium }\end{array}$ & $\begin{array}{l}\text { - Reinforce low-fat substitutions } \\
\text { - Instruct on identifying and reducing } \\
\text { dietary sodium }\end{array}$ & $\begin{array}{l}\text { - Encourage self-monitoring } \\
\text { and goal setting }\end{array}$ & $\begin{array}{l}\text { - Review home activities, reinforce } \\
\text { progress, solve problems } \\
\text { - Review food diary, provide } \\
\text { feedback }\end{array}$ & $\begin{array}{l}\text { - Address benefits of reducing } \\
\text { sodium }\end{array}$ & $\begin{array}{l}\text { - Demonstrate dietary } \\
\text { principles through } \\
\text { food tasting }\end{array}$ \\
\hline $\begin{array}{l}\text { 5. Meal } \\
\text { management }\end{array}$ & $\begin{array}{l}\text { - Reinforce low-sodium substitutions } \\
\text { - Instruct on planning healthy } \\
\text { breakfasts and } 5 \text {-step problem- } \\
\text { solving process }\end{array}$ & $\begin{array}{l}\text { - Encourage self-monitoring } \\
\text { and goal setting }\end{array}$ & $\begin{array}{l}\text { - Review home activities, reinforce } \\
\text { progress, solve problems } \\
\text { - Review food diary, provide } \\
\text { feedback }\end{array}$ & $\begin{array}{l}\text { - Address benefits of planning } \\
\text { healthy breakfasts and using } \\
\text { 5-step problem-solving process }\end{array}$ & $\begin{array}{l}\text { - Demonstrate dietary } \\
\text { principles through } \\
\text { food tasting }\end{array}$ \\
\hline $\begin{array}{l}\text { 6. Progress } \\
\text { check and } \\
\text { problem } \\
\text { solving }\end{array}$ & $\begin{array}{l}\text { - Reinforce 5-step problem-solving } \\
\text { process and SMART goal setting }\end{array}$ & $\begin{array}{l}\text { - Encourage self-monitoring } \\
\text { and goal setting }\end{array}$ & $\begin{array}{l}\text { - Reinforce progress } \\
\text { - Review food diary, provide } \\
\text { feedback }\end{array}$ & $\begin{array}{l}\text { - Elicit personal intervention } \\
\text { outcome expectations }\end{array}$ & \\
\hline 7. Whole grains & $\begin{array}{l}\text { - Instruct on identifying and increasing } \\
\text { whole grains, planning healthy } \\
\text { lunches and buying healthy foods }\end{array}$ & $\begin{array}{l}\text { - Encourage self-monitoring } \\
\text { and goal setting }\end{array}$ & $\begin{array}{l}\text { - Review home activities, reinforce } \\
\text { progress, solve problems } \\
\text { - Review food diary, provide } \\
\text { feedback }\end{array}$ & - Address benefits of whole grains & $\begin{array}{l}\text { - Demonstrate dietary } \\
\text { principles through } \\
\text { food tasting }\end{array}$ \\
\hline $\begin{array}{l}\text { 8. Nuts, seeds, } \\
\text { legumes }\end{array}$ & $\begin{array}{l}\text { - Instruct on identifying and increasing } \\
\text { nuts/seeds/legumes, planning } \\
\text { healthy dinners and preparing } \\
\text { healthy foods }\end{array}$ & $\begin{array}{l}\text { - Encourage self-monitoring } \\
\text { and goal setting }\end{array}$ & $\begin{array}{l}\text { - Review home activities, reinforce } \\
\text { progress, solve problems } \\
\text { - Review food diary, provide } \\
\text { feedback }\end{array}$ & $\begin{array}{l}\text { - Address benefits of nuts/seeds/ } \\
\text { legumes }\end{array}$ & $\begin{array}{l}\text { - Demonstrate dietary } \\
\text { principles through } \\
\text { food tasting }\end{array}$ \\
\hline $\begin{array}{l}\text { 9. Sweets, } \\
\text { added sugar, } \\
\text { alcohol }\end{array}$ & $\begin{array}{l}\text { - Instruct on identifying and reducing } \\
\text { sweets/added sugar and alcohol, } \\
\text { identifying and coping with } \\
\text { environmental cues, and planning } \\
\text { healthy snacks }\end{array}$ & $\begin{array}{l}\text { - Encourage self-monitoring } \\
\text { and goal setting }\end{array}$ & $\begin{array}{l}\text { - Review home activities, reinforce } \\
\text { progress, solve problems } \\
\text { - Review food diary, provide } \\
\text { feedback }\end{array}$ & $\begin{array}{l}\text { - Address benefits of reducing } \\
\text { sweets, added sugar and } \\
\text { alcohol, and identifying/coping } \\
\text { with environmental cues }\end{array}$ & $\begin{array}{l}\text { - Demonstrate dietary } \\
\text { principles through } \\
\text { food tasting }\end{array}$ \\
\hline 10. Eating out & $\begin{array}{l}\text { - Teach behaviour change skills for } \\
\text { eating out, and identifying and } \\
\text { coping with social cues }\end{array}$ & $\begin{array}{l}\text { - Encourage self-monitoring } \\
\text { and goal setting }\end{array}$ & $\begin{array}{l}\text { - Review home activities, reinforce } \\
\text { progress, solve problems } \\
\text { - Review food diary, provide } \\
\text { feedback }\end{array}$ & $\begin{array}{l}\text { - Address benefits of behaviour } \\
\text { change skills for eating out, and } \\
\text { identifying/coping with social } \\
\text { cues }\end{array}$ & $\begin{array}{l}\text { - Demonstrate dietary } \\
\text { principles through } \\
\text { food tasting }\end{array}$ \\
\hline $\begin{array}{l}\text { 11. Progress } \\
\text { check and } \\
\text { relapse } \\
\text { prevention }\end{array}$ & $\begin{array}{l}\text { - Teach relapse prevention, self- } \\
\text { reward and motivational tools }\end{array}$ & $\begin{array}{l}\text { - Encourage self-monitoring } \\
\text { and goal setting } \\
\text { - Teach relapse prevention, self- } \\
\text { reward and motivational tools }\end{array}$ & $\begin{array}{l}\text { Reinforce progress } \\
\text { - Review food diary, provide } \\
\text { feedback }\end{array}$ & $\begin{array}{l}\text { Elicit personal intervention } \\
\text { outcome expectations }\end{array}$ & \\
\hline
\end{tabular}

SCT construct

DASH, Dietary Approaches to Stop Hypertension; SMART, Specific, Measurable, Achievable, Relevant, Timed.

${ }^{*}$ Sessions 1,6 and 11 were individual sessions; the rest were group $\overline{\text { sessions. }}$ 
The eleven-session intensive stage began with an individual session, followed by four group sessions (with seven to ten participants), a second individual session, another four group sessions and a final individual session each session lasting approximately $1 \mathrm{~h}$. Individual sessions allowed for establishment and maintenance of participant/lifestyle coach rapport and for tailoring of curriculum instructions to individual needs and preferences. Group sessions were instructional and provided ample time for group sharing, discussion and problem solving. Each group session began with a food-tasting opportunity. The lifestyle coach offered store-purchased food samples in the first four group sessions to demonstrate DASH dietary principles; for the remaining group sessions, participants were encouraged to share foods that helped them meet the programme goals. Following food tasting, the lifestyle coach led a group discussion of the past week's home activities, barriers and problem-solving strategies. Then the coach presented new content with opportunities for individual, paired and group learning activities. Each session ended with goal setting and an explanation of home activities.

Participants who were unable to attend the originally scheduled in-person sessions were encouraged to reschedule or confer with the coach by telephone. When these options were not viable, participants received session summary and materials via email with encouragement to communicate questions and challenges to the coach.

Daily self-monitoring with a paper food diary formed the foundation for participant awareness building and dietary change, and was an important communication tool with the lifestyle coach, who provided weekly review and feedback. At a minimum, participants were encouraged to track servings of fruit, vegetables and dairy foods, fat grams and milligrams of sodium. Optional tracking included servings of whole grains, nuts, seeds and legumes, sugary foods and alcohol.

Individual telephone calls (15-20 min each) during the maintenance stage included a progress review, information sharing (as needed), problem solving and new goal setting. Participants were encouraged to continue dietary self-monitoring using either the study-supplied paper diary or a simplified check-box paper log. Participants could also use alternative electronic food tracking tools of their own choosing (e.g. MyFitnessPal application for smartphones).

\section{Mixed method intervention evaluation}

Results on the potential efficacy of the 'DASH for Asthma' intervention were previously published $^{(20)}$. Mixed methods integrating quantitative and qualitative approaches were used to evaluate acceptability and feasibility of the intervention. Quantitative data included answers to close-ended questions on a survey administered to participants and lifestyle coaches, intervention class attendance, food diary completion, session topic not covered and quality ratings of session delivery. Qualitative data included answers to open-ended questions on surveys administered to participants and lifestyle coaches.

Feedback was elicited from participants and lifestyle coaches during the intensive and maintenance stages using a survey that contained questions with open-ended and close-ended response options. The feedback from participants was anonymous. Participants who attended an in-person individual or group session were given a self-administered paper survey to rate their satisfaction (on a 5-point Likert scale) and provide qualitative comments on the content of the session, the coaching and their likelihood of making recommended dietary changes after each session. After the final maintenance-stage session, participants were asked to provide cumulative feedback on all telephone sessions using the same survey tool. The term 'respondents' is used to refer to the intervention participants who responded to the feedback survey in the Results section. The two lifestyle coaches were required to fill out a feedback survey after each in-person individual and group session and each set of telephone sessions. In the survey, they rated (on a 5-point Likert scale) and provided qualitative comments regarding how well the script and handouts conveyed information and the level of participant engagement and understanding for each topic covered. The coaches also documented the number of participants expected, the number of planned and unexcused absences, session topic not covered for individual and group sessions, and the frequency and content of maintenance telephone contacts with participants. In addition, a random $10 \%$ sample of all recorded individual and group sessions were rated for quality by the intervention manager using a standard rating scale.

Quantitative ratings, intervention class attendance, food diary completion, session topic not covered and quality ratings of session delivery were summarized with descriptive statistics using the statistical software package SAS version 9.2. Telephone session feedback surveys were returned by six participants only, precluding statistical analysis. Qualitative comments were analysed using inductive content analysis ${ }^{(25)}$. The goal of the analysis was to describe the open-ended responses at a level of generality that could facilitate understanding of the quantitative responses. A researcher (N.L.) developed an initial set of codes for the responses to all open-ended questions generated by the participants and the lifestyle coaches. Through discussion, two researchers (A.C.B. and N.L.) came to consensus on a final list of codes, their definitions and higher-order categorical groups of codes. Using this final list of codes, A.C.B. and N.L. independently coded all open-ended responses. Finally, using the coded data the researchers identified themes and analysed them for independence, coherence and consistency $^{(26,27)}$. 
Table 2 Participant ratings of intervention sessions by all sessions combined, group and individual sessions* in the 'DASH for Asthma' randomized controlled trial pilot study

\begin{tabular}{|c|c|c|c|c|c|c|}
\hline \multirow[b]{2}{*}{ Question } & \multicolumn{2}{|c|}{ All sessions ( $n$ 269) } & \multicolumn{2}{|c|}{ Group sessions ( $n$ 194) } & \multicolumn{2}{|c|}{ Individual sessions ( $n$ 75) } \\
\hline & Mean or $n$ & SD or $\%$ & Mean or $n$ & SD or $\%$ & Mean or $n$ & SD or $\%$ \\
\hline \multicolumn{7}{|c|}{ How satisfied are you with the information you received today? $\dagger$} \\
\hline Mean (SD) & 4.8 & 0.4 & 4.7 & 0.5 & 4.9 & 0.3 \\
\hline 5 & 205 & $76 \cdot 2$ & 139 & 71.7 & 66 & 88.0 \\
\hline 4 & 64 & $23 \cdot 8$ & 55 & 28.4 & 9 & $12 \cdot 0$ \\
\hline \multicolumn{7}{|c|}{ How likely are you to use the information to change how you eat? $\ddagger$} \\
\hline Mean (SD) & 4.5 & 0.7 & 4.5 & 0.7 & 4.6 & 0.7 \\
\hline 5 & 161 & $60 \cdot 3$ & 113 & $58 \cdot 6$ & 48 & 64.9 \\
\hline 4 & 91 & 34.1 & 67 & 34.7 & 24 & 32.4 \\
\hline 3 & 12 & 4.5 & 11 & $5 \cdot 7$ & 1 & 1.4 \\
\hline 2 & 1 & 0.4 & 1 & 0.5 & 0 & 0 \\
\hline 1 & 2 & 0.8 & 1 & 0.5 & 1 & 1.4 \\
\hline \multicolumn{7}{|c|}{ How effective was the lifestyle coach in leading the session?§ } \\
\hline Mean (SD) & 4.8 & 0.4 & 4.8 & 0.4 & 4.9 & 0.3 \\
\hline 5 & 226 & $84 \cdot 0$ & 161 & 83.0 & 65 & $86 \cdot 7$ \\
\hline 4 & 43 & $16 \cdot 0$ & 33 & $17 \cdot 0$ & 10 & $13 \cdot 3$ \\
\hline \multicolumn{7}{|c|}{ How satisfied were you with the session overall? $\dagger$} \\
\hline Mean (SD) & 4.8 & 0.4 & 4.8 & 0.4 & $4 \cdot 8$ & 0.4 \\
\hline 5 & 214 & 79.9 & 153 & 78.9 & 0 & 0 \\
\hline 4 & 52 & 19.4 & 39 & $20 \cdot 1$ & 61 & $82 \cdot 4$ \\
\hline 3 & 2 & 0.8 & 2 & $1 \cdot 0$ & 13 & $17 \cdot 6$ \\
\hline
\end{tabular}

DASH, Dietary Approaches to Stop Hypertension; $n$, number of responses

${ }^{*}$ Participants who attended an in-person group session or individual session were given a self-administered paper survey; response rate was $72 \%$ for group sessions and $65 \%$ for individual sessions.

†On a 5-point Likert scale ( $1=$ 'not at all satisfied', $5=$ 'extremely satisfied').

¥On a 5-point Likert scale ( $1=$ 'not at all likely', $5=$ 'extremely likely').

$\S$ On a 5-point Likert scale ( 1 = 'not at all effective', 5 = 'extremely effective').

\section{Results}

\section{Feedback on acceptability and feasibility from participant perspectives}

The participant response rate for surveys administered at the individual and group sessions was $65 \%$ and $72 \%$, respectively. Overall, the quantitative ratings showed that those who responded were highly satisfied with in-person individual and group sessions (Table 2). Qualitative feedback illuminated that respondents' satisfaction with the sessions and enhanced self-efficacy in changing eating habits were influenced by knowledge and skills mastered via awareness, goal setting, self-monitoring and problem solving; good coaching skills (reflective listening, empathy and motivational counselling); observational and social learning experience in group sessions (class members sharing foods, experiences and ideas); and personalized feedback received in individual sessions.

\section{Satisfaction with information received}

Respondents indicated very high satisfaction (mean 4.8 (SD 0.4)) with information received during both group and individual sessions. Open-ended responses showed that satisfaction was related primarily to being provided with extensive, high-quality, useful, understandable information, tools and new ideas. One respondent said, 'All information was pertinent to what I need to achieve my [dietary] goals.' Another stated, 'Lots of good, new information presented clearly.' Respondents also commented on the benefit of a good lifestyle coach (knowledgeable, supportive, good presenter) and class discussion: 'My dietitian was informative, knowledgeable and engaging'; and 'Very informative, with the class sharing their experiences.' Increased dietary awareness, skill acquisition and motivation were also mentioned as sources of satisfaction: 'Just knowing how much I intake daily help me to meet my goals'; and 'I feel good about looking towards the future with [lifestyle coach's] idea.' Compared with group sessions, the slightly higher satisfaction with individual sessions appeared to be related to the personal assistance provided during these sessions. One respondent noted, 'Great feedback on my individual progress. Encouragement about working toward goals.' Another commented, 'Went over something that was unclear to me [sugars] and discussed great things for going forward.'

\section{Likelibood of using information to change eating habits}

Respondents expressed overall high likelihood (mean 4.5 (SD 0.7)) of using information presented to change eating habits, but $5.6 \%$ of respondents provided less favourable ratings of 1,2 or 3. Motivation was the primary reason individuals gave for changing their eating habits. One respondent said, 'I definitely will change the way I eat. It is all for a new healthy me.' Another expressed that 
'I am eager to try something new.' Being provided with useful information, resources and tools was also considered to be important: 'I like the suggestions and input for new ideas - it makes success easy'; and 'I was given new ideas to help me achieve my goals.' Skill acquisition, increased awareness of dietary intake, clear or realistic goals, a good plan and confidence in the ability to change were identified as facilitators of changing eating habits: 'I found an easy way to increase vegetables'; 'I am horrified at my fat intake list (I eat junk). Cannot wait to shop responsibly'; 'A good plan with clear goals and simple steps'; and 'Knowing that I can make the changes and continuing to make changes.' Finally, respondents acknowledged the roles their environment and significant others played in changing dietary intake. One respondent commented, 'I will make little notes for my kitchen (for my spouse).' Others stated, 'I plan on sharing this information with my mom and dad especially regarding types of beans'; and 'Need to shop to have the products.' Most (twelve out of fifteen) less favourable ratings were neutral (3 on a 5-point scale). Respondent comments associated with these lower ratings included no new information in session 1 ('No new info yet'), health restrictions ('Health condition - no nuts - so will add just beans or peanut butter') and food preferences ('It would be very hard to cut down on sugar'; and 'I love salt!').

\section{Effectiveness of lifestyle coach in leading \\ the sessions}

Respondents also indicated very high satisfaction (mean 4.8 (SD 0.4)) with the effectiveness of the lifestyle coaches, with all respondents providing a rating of 4 or 5 . Satisfaction was most frequently associated with being knowledgeable, answering questions and providing useful suggestions, information, resources and feedback. One respondent commented, 'She is extremely knowledgeable and was able to answer all questions.' Another stated, 'She gave us lots of examples and built on what people were saying.' Being well prepared, organized and staying on track were also considered to be important: 'Extremely prepared as always'; and 'She stayed focused - keep us on track.' Furthermore, good coaching skills (facilitating group, reflective listening, being understanding and encouraging, and providing clear explanations) were identified as contributors to the overall effectiveness of the lifestyle coach: 'Encouraged everyone to talk so we got more ideas'; '[Coach] listens well and understands my issues. She uses her expansive knowledge of nutrition to help guide me in the direction I need to go to improve my nutrition. Her style of communication is very effective in helping me realize the changes I need to make and how to make them (e.g. reducing candy and chocolate cakes in my diet)'; '[Lifestyle coach] is very engaging with class that we feel safe in talking about our challenges and successes'; and 'Very patient and explains everything simply and clearly.'

\section{Overall satisfaction with sessions}

Respondents expressed very high satisfaction (mean 4.8 (SD 0.4)) with the sessions overall. Themes previously identified with respondents' satisfaction with information provided during the sessions were similar to the comments on overall satisfaction. Useful and easily understood information, resources and new ideas provided by the lifestyle coaches and thorough group discussion were most commonly cited. One respondent said, 'Discussions were awesome, topics easy to understand and follow.' Another stated, 'Good session - lots of new helpful information about menus and social cues.' Also mentioned were the benefits of a highly skilled lifestyle coach providing a positive learning environment, valuable learning activities and skills for behaviour change: 'Great, professional, group leader'; 'Great activity of planning a meal out with good choices'; and '[Lifestyle coach] help me understand where I am failing and help me [learn] how to solve and be proactive.' Food samples and skill demonstration were considered helpful. One respondent commented, 'Really like the food samples' and another stated 'Actually seeing how the measuring can be done. Great tips.' Finally, personal motivation contributed to overall satisfaction. Per one respondent: 'In a nutshell, this whole program was life altering and this session continued to support that. I'm able to make and sustain nutrition lifestyle changes that have been so challenging to me before.'

\section{Feedback on acceptability and feasibility from lifestyle coach perspectives}

The coach survey response rate for the individual and group sessions was $95 \%$ and $98 \%$, respectively. Overall, the two lifestyle coaches were highly satisfied with individual and group sessions, with individual sessions viewed slightly more favourably than group sessions (Table 3). With a response rate of $90 \%$, ratings of telephone sessions were positive but less favourable compared with individual and group sessions (Table 4).

The number of general lifestyle coach comments was limited, as the majority of comments focused on sessionspecific observations. Themes emerging from both general and session-specific comments showed that reasons most frequently cited for session effectiveness were high participant involvement and healthy food-tasting activities: 'Participants expressed their concerns and provided helpful solutions for each other'; 'Great discussion today ... a lot of participation on whole grains and how to build a better lunch'; and 'Participants were pleased with the low sodium food items brought in to taste... everyone enjoyed the cottage cheese and turkey ... showed them that these products still taste good with less sodium.'

Compared with the group sessions, individual sessions provided lifestyle coaches opportunities to identify and address participants' personal preferences, needs, progress and barriers: '[Participant] brought up an interesting 
Table 3 Lifestyle coach ratings of intervention sessions by all sessions combined, group and individual sessions ${ }^{\star}$ in the 'DASH for Asthma' randomized controlled trial pilot study

\begin{tabular}{|c|c|c|c|c|c|c|}
\hline \multirow[b]{2}{*}{ Question } & \multicolumn{2}{|c|}{ All sessions $(n 594)$} & \multicolumn{2}{|c|}{ Group sessions ( $n$ 155) } & \multicolumn{2}{|c|}{ Individual sessions ( $n$ 439) } \\
\hline & Mean or $n$ & SD or $\%$ & Mean or $n$ & SD or \% & Mean or $n$ & SD or \% \\
\hline \multicolumn{7}{|c|}{ How well did the script and handouts convey the information? $\dagger$} \\
\hline Mean (SD) & 4.5 & 0.6 & 4.4 & 0.6 & 4.6 & 0.6 \\
\hline 5 & 331 & $56 \cdot 5$ & 68 & 43.9 & 263 & 61.0 \\
\hline 4 & 225 & 38.4 & 75 & 48.4 & 150 & $34 \cdot 8$ \\
\hline 3 & 27 & $4 \cdot 6$ & 12 & $7 \cdot 7$ & 15 & 3.5 \\
\hline 2 & 3 & 0.5 & 0 & 0 & 3 & 0.7 \\
\hline \multicolumn{7}{|c|}{ What appeared to be the overall level of participant engagement? $\ddagger$} \\
\hline Mean (SD) & 4.4 & 0.7 & 4.4 & 0.6 & 4.5 & 0.8 \\
\hline 5 & 322 & $55 \cdot 2$ & 62 & $42 \cdot 2$ & 260 & $59 \cdot 6$ \\
\hline 4 & 192 & 32.9 & 78 & 53.1 & 114 & $26 \cdot 2$ \\
\hline 3 & 66 & 11.3 & 7 & $4 \cdot 8$ & 59 & 13.5 \\
\hline 2 & 3 & 0.5 & 0 & 0 & 3 & 0.7 \\
\hline \multicolumn{7}{|c|}{ What appeared to be the overall level of participant understanding?§ } \\
\hline Mean (SD) & 4.5 & 0.7 & 4.4 & 0.6 & 4.5 & 0.7 \\
\hline 5 & 337 & $56 \cdot 7$ & 65 & 41.9 & 272 & $62 \cdot 0$ \\
\hline 4 & 200 & 33.7 & 83 & 53.6 & 117 & $26 \cdot 7$ \\
\hline 3 & 57 & 9.6 & 7 & 4.5 & 50 & 11.4 \\
\hline \multicolumn{7}{|c|}{ How effective was the food-tasting opportunity?\| ( $n$ 39) } \\
\hline Mean (SD) & & & 4.5 & 0.6 & & \\
\hline 5 & & & 22 & 56.4 & & \\
\hline 4 & & & 15 & 38.5 & & \\
\hline 3 & & & 2 & $5 \cdot 1$ & & \\
\hline \multicolumn{7}{|c|}{ How effective was the review of the previous session and home activities?"I ( $n$ 36) } \\
\hline Mean (SD) & & & 4.1 & 0.7 & & \\
\hline 5 & & & 9 & $25 \cdot 0$ & & \\
\hline 4 & & & 20 & 55.6 & & \\
\hline 3 & & & 7 & $19 \cdot 4$ & & \\
\hline
\end{tabular}

DASH, Dietary Approaches to Stop Hypertension; $n$, number of responses; NA, not applicable.

The first three questions were repeated for the number of content areas in each session, whereas the last two questions were asked once per session

*Lifestyle coaches were asked to complete a feedback survey after each in-person group session and individual session; response rate was $98 \%$ for group sessions and $95 \%$ for individual sessions.

†On a 5 -point Likert scale ( $1=$ 'not well at all', $5=$ 'extremely well').

¥On a 5 -point Likert scale ( $1=$ 'not at all engaged', $5=$ 'extremely engaged').

§On a 5 -point Likert scale ( $1=$ 'no one understood anything', $5=$ 'everyone understood everything')

IOn a 5 -point Likert scale ( $1=$ 'not at all effective', $5=$ 'extremely effective').

point about feeling guilt and how that can be a negative thought... May be good to add guilt to our list'; 'Participant is meeting all goals. [We] incorporated a SMART (Specific, Measurable, Achievable, Relevant, Timed) goal and daily target for fruits and vegetables for the next 2 weeks'; and '[We had] detailed discussion via phone regarding barriers and solutions to increase fruit and vegetable consumption while at work.'

Coaches provided a limited number of comments to open-ended questions. The comments suggested that during the maintenance stage coaches had additional opportunities to evaluate participants' progress and address their barriers: 'Participant was very engaged throughout the study. She continued to make improvements with her diet that coincided with the DASH goals even after the class sessions. Participant provided me with a lot of feedback on the changes she was making'; and 'Participant had a lot of personal issues going on during the end of the study so his focus on his plan was deferred. He was able to bounce back towards the end and we had more to discuss during the phone sessions in regards to his progress towards his goals.'
Although the vast majority of participant and lifestyle coach comments were positive, some areas for improvement were also noted, including more visuals (e.g. visuals of fruit, vegetable and cheese servings), electronic dietary tracking tools, more guides with ethnic foods and more examples of fruit/vegetable servings.

\section{Dose delivered and dose received}

Dose delivered

In general, most sessions were conducted per protocol. Among a total of 116 in-person individual sessions, 106 covered all planned topics, three sessions did not cover one topic and one session did not cover any of the planned topics (coach had to use the time to review previous missed sessions). Six sessions had missing data. Of forty in-person group sessions, thirty-seven covered all planned topics, two sessions did not cover one topic and one session had missing data. During the maintenance stage, twenty-four out of forty-one sets of telephone sessions covered all planned topics, eight sets did not cover one topic, five did not cover two topics and four 
Table 4 Lifestyle coach ratings of telephone sessions* in the 'DASH for Asthma' randomized controlled trial pilot study

\begin{tabular}{|c|c|c|}
\hline Question & Mean or $n$ & SD or $\%$ \\
\hline \multicolumn{3}{|c|}{$\begin{array}{l}\text { How well did the instructions in the script guide your counseling? } \\
(n \text { 138) }\end{array}$} \\
\hline Mean (SD) & 3.8 & 0.6 \\
\hline 5 & 9 & 6.5 \\
\hline 4 & 89 & 64.5 \\
\hline 3 & 40 & $29 \cdot 0$ \\
\hline \multicolumn{3}{|c|}{ What appeared to be the level of participant engagement? $\ddagger(n 134)$} \\
\hline Mean (SD) & 3.6 & 0.8 \\
\hline 5 & 20 & 14.9 \\
\hline 4 & 45 & 33.6 \\
\hline 3 & 64 & $47 \cdot 8$ \\
\hline 2 & 5 & 3.7 \\
\hline \multicolumn{3}{|c|}{ How helpful did this discussion appear to be to participants?§ ( $n$ 134) } \\
\hline Mean (SD) & 3.5 & 0.8 \\
\hline 5 & 17 & $12 \cdot 7$ \\
\hline 4 & 40 & 29.9 \\
\hline 3 & 69 & 51.5 \\
\hline 2 & 8 & $6 \cdot 0$ \\
\hline
\end{tabular}

DASH, Dietary Approaches to Stop Hypertension; $n$, number of responses to question.

These three questions were repeated for the number of content areas in each telephone session.

*Lifestyle coaches were asked to complete a feedback survey after the last telephone session for each participant; response rate was $90 \%$.

fOn a 5-point Likert scale ( $1=$ 'not well at all', $5=$ 'extremely well').

‡On a 5-point Likert scale ( $1=$ 'not at all engaged', 5 = 'extremely engaged').

$\S$ On a 5-point Likert scale ( $1=$ 'not at all helpful', $5=$ 'extremely helpful').

had missing data. Reasons for not covering topics included limited time, content already covered in previous session and lack of participant engagement during the maintenance stage.

\section{Dose received}

Dose received was captured by participant class attendance and self-monitoring completion. The attendance rate at the initially scheduled intensive-stage sessions ranged from $65 \%$ to $87 \%$ (Table 5). All participants who did not attend the sessions as scheduled made up sessions 1-5 and 82-93\% made up sessions 6-11, either in person (0-22\% of the make up sessions), by telephone (0-83\%) or through email $(0-100 \%)$. Of the forty-six intervention participants, $41 \%, 35 \%$ and $13 \%$ completed three, two and one telephone session(s), respectively, and $11 \% \mathrm{did}$ not complete any telephone session during the 3-month maintenance stage.

Almost all (44/46, $96 \%$ ) participants used food diaries to self-monitor their food intake. Numbers of weeks of selfmonitoring were as follows: fruit and vegetables (median 8 (interquartile range (IQR) 2) out of 9 expected), dairy (median 8 (IQR 3) out of 9), fat (median 6 (IQR 6) out of 8) and sodium (median 6 (IQR 5 ) out of 7). The numbers of expected weeks varied because these goals were introduced at different times. The median number of total days of self-monitoring from week 3 to week 11 was 56 (IQR 23) out of 63. Seventeen (37\%) of the forty-six participants logged every day.

\section{Fidelity}

Overall quality and adherence to script of individual and group sessions and overall quality of telephone sessions were high. For individual and group sessions combined, mean score of overall quality was 4.6 (sD 0.3 ) out of 5 and mean score of overall adherence to script was $14 \cdot 1$ (SD 1·1) out of 15 . For telephone sessions, mean score of overall quality was 4.2 (SD 0.4) out of 5 .

\section{Discussion}

We demonstrated that an SCT-based intervention to promote adherence to the DASH eating pattern was highly feasible and acceptable to participants and lifestyle coaches, based on high class attendance (65-87\% for initially scheduled sessions), high self-monitoring rate (96\%), and positive quantitative and qualitative feedback from participants (65-72\% response rate) and coaches (95-98\% response rate). Quantitative ratings showed high satisfaction with the in-person intensive stage of the programme, and qualitative feedback illuminated that the salient features supporting participant progress as well as overall programme satisfaction were participants' enhanced knowledge and behaviour capabilities, increased self-efficacy, good coaching, personalized feedback and participant engagement.

SCT provided a framework for supporting dietary behaviour change through tasks that inform, enable, guide and motivate individuals to modify what they eat ${ }^{(28)}$. The present study uniquely examined the importance of theoretical constructs in programme satisfaction and acceptability from both the participant and lifestyle coach perspectives. Participants consistently identified enhanced behavioural capability and increased self-efficacy as the greatest source of satisfaction with both group and individual sessions. These constructs seemed to be facilitated by SCT-based intervention tasks, such as SMART goal setting, self-monitoring, progress review, personalized feedback and problem solving. This finding is consistent with previous evidence showing the importance of these theoretical-based intervention components in improving self-efficacy and health behaviours ${ }^{(29,30)}$. Some studies have demonstrated that self-regulation skills (e.g. goal setting and self-monitoring) are the most powerful skills needed by participants to change their dietary behaviours ${ }^{(31,32)}$. In addition to self-regulation skills, personalized feedback ${ }^{(33,34)}$ and problem solving ${ }^{(35)}$ have also been identified as effective strategies for supporting lifestyle behaviour changes.

Although self-reward was included as a strategy for the intervention and has previously been noted as an important predictor of self-efficacy and healthy eating behaviours ${ }^{(36)}$, participants in our study seldom mentioned self-reward in their feedback. Another study also noted that self-reward was seldom used by 


\begin{tabular}{|c|c|c|c|c|c|c|c|c|c|c|c|}
\hline & \multicolumn{11}{|c|}{ Session (\%) } \\
\hline & I1 & G2 & G3 & G4 & G5 & 16 & G7 & G8 & G9 & G10 & I11 \\
\hline Session attended, as initially scheduled ${ }^{*}$ & 87 & 80 & 76 & 65 & 70 & 83 & 72 & 70 & 72 & 81 & 76 \\
\hline $\begin{array}{l}\text { Make up sessions } \\
\text { Options to make up sessionst }\end{array}$ & 100 & 100 & 100 & 100 & 100 & 88 & 92 & 93 & 92 & 89 & 82 \\
\hline In-person individual & 17 & 22 & 9 & 19 & 22 & 14 & 0 & 0 & 0 & 0 & 11 \\
\hline Telephone & 83 & 45 & 73 & 31 & 7 & 14 & 17 & 8 & 0 & 0 & 56 \\
\hline Email§ & 0 & 33 & 18 & 50 & 71 & 72 & 83 & 92 & 100 & 100 & 33 \\
\hline
\end{tabular}

DASH, Dietary Approaches to Stop Hypertension; I, individual session; G, group session.

*Percentage of total intervention participants by session.

†Percentage of participants who missed the session as initially scheduled.

$\ddagger$ Percentage of participants who made up sessions.

$\S$ Lifestyle coaches emailed session summary and materials and responded to participants' questions if any.

participants in achieving their goals for losing weight via improving diet and physical activity ${ }^{(29)}$. In our study, self-reward was introduced at the last individual session as a strategy to increase motivation and prevent relapse; however, it is possible that participants did not understand how to utilize this strategy well. Future studies may place more emphasis on helping participants build confidence to effectively use this strategy and avoid negative guilty feelings.

From a lifestyle coach's point of view, participant involvement and engagement were viewed as a key to effective sessions. This is in line with findings from other studies showing that participant engagement and participation are important to the success of behaviour change interventions $^{(37,38)}$. In our study, coaches frequently identified food tasting (tasty, new options, good variety) as a facilitator for participant involvement and engagement in group sessions. The opportunities of one-on-one counselling provided by the individual sessions helped maintain participant engagement and coach/participant rapport. Participant feedback on intervention improvement (e.g. reducing the amount of information, adding more new information and more information on ethnic foods) suggested that future interventions should increase consideration of individuals' pace and individual needs in order to further engage participants. This supports the necessity of individual sessions that allow one-on-one counselling to address participants' personal needs.

Class attendance and use of self-monitoring were relatively high compared with an estimated adherence rate of $50 \%$ to diet, drug and exercise regimens among individuals with chronic diseases ${ }^{(39)}$, which may indirectly reflect participants' satisfaction with the programme. Research has shown that high session attendance is associated with behaviour change ${ }^{(40,41)}$. The completion rate of maintenance-stage telephone sessions was not as high as the in-person class attendance rate. Future interventions may consider implementing strategies such as shorter but more frequent telephone sessions and different session formats (e.g. Internet, email, mobile texting or similar electronic means) to keep participants engaged in the maintenance stage.
It is important to note that the current study has some potential limitations. There was a possibility of selective response to the feedback surveys among participants and lifestyle coaches. Participants who responded might have been those who were more committed and more positive towards the intervention or the intervention goals. To mitigate this possibility, all participants who attended the in-person individual and group sessions were highly encouraged by their coaches to complete the survey at the end of each session and all participant evaluations were anonymous. The intervention consists of three individual and eight group sessions, so there is a possibility of fatigue among intervention participants and the coaches to respond to all the surveys. In addition, given the anonymous feature of participants' feedback, we could not investigate whether there was a difference in session attendance, frequency of self-monitoring and intervention outcomes between those who responded and those who did not. Another limitation was the paucity of participant feedback on experiences with the telephone sessions. Minimal survey completion precluded analysis of participant satisfaction with this component of the programme. Identifying methods (e.g. surveys conducted over the telephone or incentives for survey completion) to encourage participants to provide feedback on this programme component could have provided better insight into participant experiences with the maintenance stage of the programme. In addition, participants in the study may have been more motivated to make dietary changes than unselected individuals in the general population; thus the findings may not be generalizable.

Despite these limitations, results from the present study provide context for why the 'DASH for Asthma' intervention increased participants' adherence to the DASH eating plan and the proportion of those achieving minimal clinically important improvement in asthma control ${ }^{(20)}$ and inform how to refine the intervention and design future behavioural interventions in patients with uncontrolled asthma. Currently, there is a dearth of randomized controlled trials investigating whether behavioural interventions promoting a healthy dietary pattern can 
improve asthma control. Lessons learned from the current study include: (i) SCT is a useful theoretical framework for designing a potentially effective DASH behavioural intervention that was also feasible and highly acceptable to both participants and lifestyle coaches; (ii) both group and individual sessions were considered useful by participants and lifestyle coaches in that group sessions provided opportunities for team support and social learning while individual sessions allowed personal tailoring and helped maintain participant engagement and coach/participant rapport; (iii) food tasting was the activity considered most important for observational learning and participant engagement by participants and lifestyle coaches; (iv) participants valued visuals (e.g. food measuring and serving sizes) as effective tools for demonstration and communication; and (v) lifestyle coaches viewed telephone contacts during the maintenance stage as necessary in that they provided additional opportunities to track participants' progress, address barriers and prevent relapse.

These lessons could help determine which programme components are most valuable to participants and lifestyle coaches, and help refine future full trials to improve the experience of both participants and coaches. Furthermore, the findings of the current study may also encourage and inform other lifestyle interventions to improve overall diet in patients with asthma. Such interventions are in demand given the encouraging epidemiological evidence on the protective effects of certain food groups (e.g. fruit, vegetables and fish) and healthy dietary patterns (e.g. Mediterranean diet) on asthma control ${ }^{(5,42)}$.

\section{Conclusion}

The present study demonstrates that a 6-month SCT-based dietary intervention was feasible to teach nutrition and behaviour modification skills and coach participants to make sustained dietary changes towards the DASH eating pattern. Feedback from both participants and lifestyle coaches indicated high satisfaction with the 11-week intensive, in-person component of the programme. Key contributors to satisfaction were participants' enhanced behaviour capabilities, increased self-efficacy, good coaching and participant engagement. The relatively high class attendance and food diary completion rates may reflect participants' satisfaction with the programme as well as their perceived benefit of the programme. Strategies to address the noted areas for improvement and promote sustained participation in the maintenance stage are needed in future research.

\section{Acknowledgements}

Acknowledgements: The authors thank all participants for their continuing support of the project. Financial support: This research was supported by the National Heart, Lung, and Blood Institute (grant number R34 HL108753) and internal funding from the Palo Alto Medical Foundation Research Institute. The content is solely the responsibility of the authors and does not necessarily represent the official views of the National Heart, Lung, and Blood Institute. No sponsor or funding source had a role in the design or conduct of the study; collection, management, analysis or interpretation of the data; or preparation, review or approval of the manuscript. Conflict of interest: None. Authorship: A.C.B. and N.L. are dual first authors. J.M., C.A.C., S.R.W., A.S.B. and P.S. formulated the research questions and/or designed the study; A.C.B. and N.L. analysed the data; all authors participated in manuscript writing and/or critical revisions for important intellectual content; J.M. obtained funding for the study. Ethics of human subject participation: This study was conducted according to the guidelines laid down in the Declaration of Helsinki and all procedures involving human subjects/patients were approved by an Institutional Review Board of the Kaiser Foundation Research Institute in Northern California and the study Data and Safety Monitoring Board. Written informed consent was obtained from all subjects/patients.

\section{References}

1. Global Asthma Network (2014) The Global Asthma Report 2014, http://www.globalasthmareport.org/resources/ Global_Asthma_Report_2014.pdf (accessed March 2015).

2. Akinbami LJ, Moorman JE, Bailey C et al. (2012) Trends in Asthma Prevalence, Health Care Use, and Mortality in the United States, 2001-2010. Hyattsville, MD: National Center for Health Statistics.

3. McKeever TM \& Britton J (2004) Diet and asthma. Am J Respir Crit Care Med 170, 725-729.

4. Kim JH, Ellwood PE \& Asher MI (2009) Diet and asthma: looking back, moving forward. Respir Res 10, 49.

5. Barros R, Moreira A, Fonseca J et al. (2008) Adherence to the Mediterranean diet and fresh fruit intake are associated with improved asthma control. Allergy 63, 917-923.

6. Iikura M, Yi S, Ichimura Y et al. (2013) Effect of lifestyle on asthma control in Japanese patients: importance of periodical exercise and raw vegetable diet. PLoS One $\mathbf{8}$, e68290.

7. Barros R, Moreira A, Fonseca J et al. (2011) Dietary intake of $\alpha$-linolenic acid and low ratio of $n-6: n-3$ PUFA are associated with decreased exhaled $\mathrm{NO}$ and improved asthma control. BrJ Nutr 106, 441-450.

8. Chatzi L, Torrent M, Romieu I et al. (2008) Mediterranean diet in pregnancy is protective for wheeze and atopy in childhood. Thorax 63, 507-513.

9. Nagel G, Weinmayr G, Kleiner A et al. (2010) Effect of diet on asthma and allergic sensitisation in the International Study on Allergies and Asthma in Childhood (ISAAC) Phase Two. Thorax 65, 516-522.

10. Arvaniti F, Priftis KN, Papadimitriou A et al. (2011) Adherence to the Mediterranean type of diet is associated with lower prevalence of asthma symptoms, among 10-12 years old children: the PANACEA study. Pediatr Allergy Immunol 22, 283-289.

11. Karanja NM, Obarzanek E, Lin PH et al. (1999) Descriptive characteristics of the dietary patterns used in the Dietary Approaches to Stop Hypertension Trial. DASH Collaborative Research Group. J Am Diet Assoc 99, 8 Suppl., S19-S27. 
12. US Department of Agriculture \& US Department of Health and Human Services (2010) Dietary Guidelines for Americans, 2010, 7th ed. Washington, DC: US Government Printing Office.

13. Sacks FM, Svetkey LP, Vollmer WM et al. (2001) Effects on blood pressure of reduced dietary sodium and the Dietary Approaches to Stop Hypertension (DASH) diet. DASH-Sodium Collaborative Research Group. N Engl J Med 344, 3-10.

14. Blumenthal JA, Babyak MA, Hinderliter A et al. (2010) Effects of the DASH diet alone and in combination with exercise and weight loss on blood pressure and cardiovascular biomarkers in men and women with high blood pressure: the ENCORE study. Arch Intern Med 170, 126-135.

15. Lin PH, Appel LJ, Funk K et al. (2007) The PREMIER intervention helps participants follow the Dietary Approaches to Stop Hypertension dietary pattern and the current Dietary Reference Intakes recommendations. J Am Diet Assoc 107, $1541-1551$.

16. Couch SC, Saelens BE, Levin L et al. (2008) The efficacy of a clinic-based behavioral nutrition intervention emphasizing a DASH-type diet for adolescents with elevated blood pressure. J Pediatr 152, 494-501.

17. Fung TT, Chiuve SE, McCullough ML et al. (2008) Adherence to a DASH-style diet and risk of coronary heart disease and stroke in women. Arch Intern Med 168, 713-720.

18. Liese AD, Nichols M, Sun X et al. (2009) Adherence to the DASH Diet is inversely associated with incidence of type 2 diabetes: the insulin resistance atherosclerosis study. Diabetes Care 32, 1434-1436.

19. Ma J, Strub P, Lavori PW et al. (2013) DASH for Asthma: a pilot study of the DASH diet in not-well-controlled adult asthma. Contemp Clin Trials 35, 55-67.

20. Ma J, Strub P, Lv N et al. (2015) Pilot randomized trial of a healthy eating behavioural intervention in uncontrolled asthma. Eur Respir J (Epublication ahead of print version).

21. Parikh A, Lipsitz SR \& Natarajan S (2009) Association between a DASH-like diet and mortality in adults with hypertension: findings from a population-based followup study. Am J Hypertens 22, 409-416.

22. Svetkey LP, Harsha DW, Vollmer WM et al. (2003) Premier: a clinical trial of comprehensive lifestyle modification for blood pressure control: rationale, design and baseline characteristics. Ann Epidemiol 13, 462-471.

23. Look ARG, Wadden TA, West DS et al. (2006) The Look AHEAD study: a description of the lifestyle intervention and the evidence supporting it. Obesity (Silver Spring) 14, 737-752.

24. Bandura A (1986) Social Foundations of Thought and Action: A Social Cognitive Theory. Englewood Cliffs, NJ: Prentice Hall.

25. Elo S \& Kyngas H (2008) The qualitative content analysis process. J Adv Nurs 62, 107-115.

26. Miles M \& Huberman M (1994) Qualitative Data Analysis: An Expanded Sourcebook, 2nd ed. Thousand Oaks, CA: SAGE Publications Inc.

27. Graneheim UH \& Lundman B (2004) Qualitative content analysis in nursing research: concepts, procedures and measures to achieve trustworthiness. Nurse Educ Today 24, 105-112.
28. Bandura A (1977) Self-efficacy: toward a unifying theory of behavioral change. Psychol Rev 84, 191-215.

29. Morgan PJ, Scott HA, Young MD et al. (2014) Associations between program outcomes and adherence to Social Cognitive Theory tasks: process evaluation of the SHED-IT community weight loss trial for men. Int J Behav Nutr Phys Act 11, 89.

30. Pearson ES (2012) Goal setting as a health behavior change strategy in overweight and obese adults: a systematic literature review examining intervention components. Patient Educ Couns 87, 32-42.

31. Anderson-Bill ES, Winett RA \& Wojcik JR (2011) Social cognitive determinants of nutrition and physical activity among web-health users enrolling in an online intervention: the influence of social support, self-efficacy, outcome expectations, and self-regulation. J Med Internet Res 13, e28.

32. Anderson ES, Winett RA \& Wojcik JR (2007) Self-regulation, self-efficacy, outcome expectations, and social support: social cognitive theory and nutrition behavior. Ann Behav Med 34, 304-312.

33. Spahn JM, Reeves RS, Keim KS et al. (2010) State of the evidence regarding behavior change theories and strategies in nutrition counseling to facilitate health and food behavior change. J Am Diet Assoc 110, 879-891.

34. Walker RJ, Smalls BL, Bonilha HS et al. (2013) Behavioral interventions to improve glycemic control in African Americans with type 2 diabetes: a systematic review. Ethn Dis 23, 401-408.

35. Cotter AP, Durant N, Agne AA et al. (2014) Internet interventions to support lifestyle modification for diabetes management: a systematic review of the evidence. J Diabetes Complications 28, 243-251.

36. Byrd-Bredbenner C, Abbot JM \& Cussler E (2011) Relationship of social cognitive theory concepts to mothers' dietary intake and BMI. Matern Child Nutr 7, 241-252.

37. Brace AM, Padilla HM, DeJoy DM et al. (2014) Applying RE-AIM to the evaluation of FUEL Your Life: a worksite translation of DPP. Health Promot Pract 16, 28-35.

38. Tussing-Humphreys L, Thomson JL, Mayo T et al. (2013) A church-based diet and physical activity intervention for rural, lower Mississippi Delta African American adults: Delta Body and Soul effectiveness study, 2010-2011. Prev Chronic Dis 10, E92.

39. World Health Organization (2003) Adherence to long-term therapies: evidence for action. http://www.who.int/chp/ knowledge/publications/adherence_report/en/ (accessed August 2015).

40. Tinker LF, Rosal MC, Young AF et al. (2007) Predictors of dietary change and maintenance in the Women's Health Initiative Dietary Modification Trial. J Am Diet Assoc 107, $1155-1166$.

41. Hollis JF, Gullion CM, Stevens VJ et al. (2008) Weight loss during the intensive intervention phase of the weight-loss maintenance trial. Am J Prev Med 35, 118-126.

42. Lv N, Xiao L \& Ma J (2014) Dietary pattern and asthma: a systematic review and meta-analysis. J Asthma Allergy 7, 105-121. 